\title{
Erratum to: Molecular characterization of the RNA-dependent RNA polymerase from groundnut ringspot virus (genus Tospovirus, family Bunyaviridae)
}

\author{
A. G. M. Bertran · A. S. Oliveira $\cdot$ T. Nagata \\ R. O. Resende
}

Published online: 21 June 2011

(c) Springer-Verlag 2011

\section{Erratum to: Arch Virol \\ DOI 10.1007/s00705-011-0973-4}

The tospoviruses Groundnut ringspot virus (GRSV) and Tomato chlorotic spot virus (TCSV) are very similar both in terms of biological properties and nucleotide sequences. They also cross-react in immunological detection assays, hence are grouped in the same serogroup [1, 2]. Although classified as different tospovirus species, they share high identity levels in their genomic and protein sequences. Tospovirus isolates have been maintained for several years and routinely checked in our laboratories via DAS-ELISA using polyclonal antibodies, which occasionally may lead to mistakes in species identification depending on the virus titers in positive controls and samples. Using an isolate identified by DAS-ELISA as GRSV, we cloned and sequenced the complete L RNA (GenBank accession no. HQ700667.) of this sample (Archives of Virology, DOI 10.1007/s00705-011-0973-4). Considering that there were no other L RNA sequences available for comparison to either GRSV or TCSV at the time of submission of our article, we had no reason to doubt the identity of our isolate as GRSV. Nevertheless, when new GRSV and TCSV L RNA sequences obtained by Webster et al. [3] became

The online version of the original article can be found under doi:10.1007/s00705-011-0973-4.

A. G. M. Bertran · A. S. Oliveira · T. Nagata .

R. O. Resende ( $\square)$

Laboratory of Plant Virology, Department of Cellular Biology,

Biological Sciences Institute, University of Brasília,

Campus Universitário Darcy Ribeiro, Asa Norte,

Brasília, Distrito Federal 70910-900, Brazil

e-mail: rresende@unb.br available (accession HQ644142. for the full-length L RNA sequence from their isolate, and HQ634677-9. and HQ634680. for the partial sequences from GRSV and TCSV L RNA's respectively), comparisons were made between their sequences and our GRSV L RNA sequence. A $82.1 \%$ nucleotide identity value was found between the two full-length GRSV L RNA sequences (HQ700667. and HQ644142.), whereas a 95.5\% nucleotide identity was found between our sequence and their partial TCSV L RNA sequence (HQ634680.). When the same total RNA pool from infected Datura stramonium plants was used for the characterization of the $\mathrm{N}$ gene sequencing, we found that the $\mathrm{N}$ gene of our isolate was $94.1-94.8 \%$ identical by pairwise comparison to other nucleotide sequences of TCSV deposited in GenBank. The highest identity to the N genes of GRSV available was $80.9 \%$. Therefore, we concluded that our L RNA sequence published in Archives of Virology was, in fact, from a TCSV isolate and not from a GRSV isolate. Further sequencing of the other genomic segments also confirmed the TCSV identity present in our sample. It is important to point out that this fact neither invalidates our molecular analysis of the $\mathrm{L}$ protein presented in the published paper, nor the suggestion that protein L-based trees may have better accuracy in determining the evolutionary distance between species. Readers of the paper are advised to keep in mind our erratum, while reading the manuscript. The GenBank accession of our L RNA sequence has also been updated.

\section{References}

1. De Avila AC, Huguenot C, Resende RO, Kitajima EW, Goldbach RW, Peters D (1990) Serological differentiation of 20 isolates of Tomato spotted wilt virus. J Gen Virol 71:2801-2807 
2. De Avila AC, de Haan P, Kormelink R, Resende RO, Goldbach R, Peters D (1993) Classification of tospoviruses based on phylogeny of nucleoprotein gene sequences. J Gen Virol 74(Pt2): 153-159
3. Webster CG, Reitz SR, Perry KL, Adkins S (2011) A natural M RNA reassortant arising from two species of plant- and insectinfecting bunyaviruses and comparison of its sequence and biological properties to parental species. Virology 413(2):216-225 